JURNAL ILMIAH KOMPUTERISASI AKUNTANSI, Vol. 14, No. 2, Desember 2021, pp.340 - 349

p-ISSN : 1979-116X (print)

e-ISSN : 2614-8870 (online)

http://journal.stekom.ac.id/index.php/kompak

- page 340

\title{
Faktor-faktor yang mempengaruhi perpindahan merek Asus ke merek lain
}

\author{
Tini Utami ${ }^{1}$, Suprihono Setyawan ${ }^{2}$, Ahmad Suwondo $^{3}$ \\ ${ }^{1}$ Politeknik Bumi Akpelni \\ e-mail : Utami.tini@yahoo.co.id / 08122532912 \\ ${ }^{2,3}$ Universitas Selamat Sri \\ wawan.suprihonosetyawan@gmail.com
}

\section{ARTICLE INFO}

Article history:

Received 30 September 2021

Received in revised form 2 November 2021

Accepted 10 November 2021

Available online 1 Desember 2021
This study aims to examine "Anatysis of the influence of dissatisfaction, product attributes, and the need for variation, on the switching of the Asus brand ". This data research used a questionnaire with a scale of 1-5 with a sample of 96 respondents. This sampling technique uses a non probability sampling with technique purposive sampling. The data obtained were then analyzed with the SPSS . The results of this study partially (1) Dissatisfaction has a positive and significant effect on brand switching based on the value of $t$ count $>$ t table that is $3.575>1.662$ with a significant $0.001<0.05$. (2) Product attributes have a positive and significant effect on brand switching based on the value of $t$ count $>t$ table, namely $2.362>1.662$ with a significant $0.002<0.05$. (3). The need to look for variations has a positive and significant effect on brand switching based on the $t$ count $>t$ table, namely $6.472>1.662$ with a significant 0.000 $<0.05$. (4) Simultaneously, dissatisfaction, product attributes, and the need for variation have a positive and significant effect on brand switching. Based on the calculated $F$ value $<F$ table that is 111.918> 3.945 with a significant $0.000<0.005$. Based on Adjusted $R$ Square that is equal to 0.778. In this case, it means that $77.8 \%$ of the variation in the brand switching variable is explained by the variables of dissatisfaction, product attributes, and the need to seek variation. Meanwhile, the remaining $22.2 \%$ is explained by other variables outside the model

Keywords: dissatisfaction, product attributes and, the need to find variations

ABSTRACT

Received Sep 30, 2021; Revised Nov 2, 2021; Accepted Nov 10, 2021 


\section{Pendahuluan}

Sebagai sebuah alat komunikasi saat ini maka telepon genggam atau smartphone haruslah mempunyau unjuk kerja yang bisa mendukung setiap keinginan penggunanya dalam hal pemenuhan kebutuhan berkomunikasi berbasis alat komunikasi pintar. Saat sekarang ini berbagai merek smartphone bisa kita jumpai dipasaran dengan berbagai keunggulan dan kehandalannya yang dimana salah satunya adalah merek Asus. Adanya permintaan dari masyarakat yang selalu menginginkan produk yang kompetitif baik harga maupun model inilah yang membuat konsumen semakin bebas menjatuhkan pilihan dan rentan melakukan perilaku perpindahan merek. Dalam tabel dibawah ini tergambar bawah ada salah satu merek yang mengalami kelesuan tingkat penjualan dengan berbagai macam alasannya.

Tabel.1Penjualan Smartphone (dalam prosen) Periode 2017-2020

\begin{tabular}{|c|c|r|l|r|c|c|c|c|}
\hline & \multicolumn{2}{|c|}{2017} & \multicolumn{2}{c|}{2018} & \multicolumn{2}{c|}{2019} & \multicolumn{2}{c|}{2020} \\
\hline No & Merek & $(\%)$ & Merek & $(\%)$ & Merek & $(\%)$ & Merek & $(\%)$ \\
\hline 1 & Samsung & $43,4 \%$ & Samsung & $46,4 \%$ & Samsung & $48,6 \%$ & Samsung & $45,8 \%$ \\
\hline 2 & Lenovo & $10,9 \%$ & Oppo & $5,1 \%$ & Oppo & $11,2 \%$ & Oppo & $16,6 \%$ \\
\hline 3 & Iphone & $5,8 \%$ & Asus & $4,7 \%$ & Xiaomi & $5,5 \%$ & Vivo & $14,3 \%$ \\
\hline 4 & Asus & $4,0 \%$ & Xiaomi & $4,1 \%$ & Asus & $4,3 \%$ & Asus & $3,6 \%$ \\
\hline 5 & Xiaomi & $3,2 \%$ & Lenovo & $3,8 \%$ & Vivo & $4,3 \%$ & Xiaomi & $2,9 \%$ \\
\hline
\end{tabular}

Sumber : pusat penjualan smartphone di Semarang, 2021

Tabel.1 menunjukkan di tahun 2017 penjualan Asus berada di peringkat 4 dibawah Samsung, Lenovo dan Iphone, ditahun 2018 Asus mengalami peningkatan peringkat meski penjualannya menjadi 4,7\% dibawah Samsung dan pendatang baru Oppo, di tahun 2019 penjualan Asus kembali turun di angka 4,3\% dibawah Samsung, Oppo dan Xiomi dan ditahun 2020 Asus kembali mengalami penurunan di angka 3,6\% masih dibawah Samsung, Oppo dan Vivo. Ini membuktikan adanya indikasi terjadi penurunan yang signifikan serta adanya sinyal dari konsumen untuk pindah ke produk lain.

Lebih lanjut tujuan dari penelitian ini adalah ingin mendapatkan pengetahuan yang lebih mendalam dengan didukung bukti-bukti ilmiah adanya faktor-faktor yang mempengaruhi seseorang berpindah merek smartphone Asus ke merek lain.

\section{Metodologi Penelitian}

Dijelaskan lebih lanjut bahwa penelitian ini memakai metode analisis deskriptif kuantitatif, dengan metode penelitian adalah metode survey. Metode survey adalah penelitian yang mengambil sample dari suatu populasi (Sugiono, 2010).

Obyek penelitian ini adalah semua pembeli smartphone yang ada di pusat perbelajaan smartphone di Kota Semarang dengan jumlah responden sebanyak 96 orang. Selanjutnya analisis data yang akan diuraikan akan di uraikan dengan beberapa uji

\section{Tinjauan Pustaka}

\subsection{Perpindahan Merek}

Perpindahan merek (brand switching) adalah pola pembelian yang dikarakteristikkan dengan perubahan atau pergantian dari satu merek ke merek yang lain. (Peter dan Olson, 2014). 


\subsection{Ketidakpuasan}

Ketidakpuasan konsumen merupakan tolak ukur untuk menentukan loyalitas pelanggan. Konsep lain ketidakkepuasan konsumen adalah perasaan kecewa seseorang yang muncul setelah membandingkan antara kinerja (hasil) produk yang dipikirkan terhadap kinerja yang diharapkan, (Kotler dan Keller, 2016).

\subsection{Atribut Produk}

Atribut produk adalah unsur-unsur produk yang dipandang penting oleh konsumen dan dijadikan dasar pengambilan keputusan pembelian (Tjiptono, 2016).

\subsection{Kebutuhan Mencari Variasi}

Kebutuhan mencari variasi dapat dijelaskan sebagai sebuah keinginan untuk membeli merek yang lain dari sebelumnya karena adanya keinginan baru, atau timbulnya rasa bosan pada diri konsumen Peter dan Olson,2014).

\subsection{Pengembangan Model}

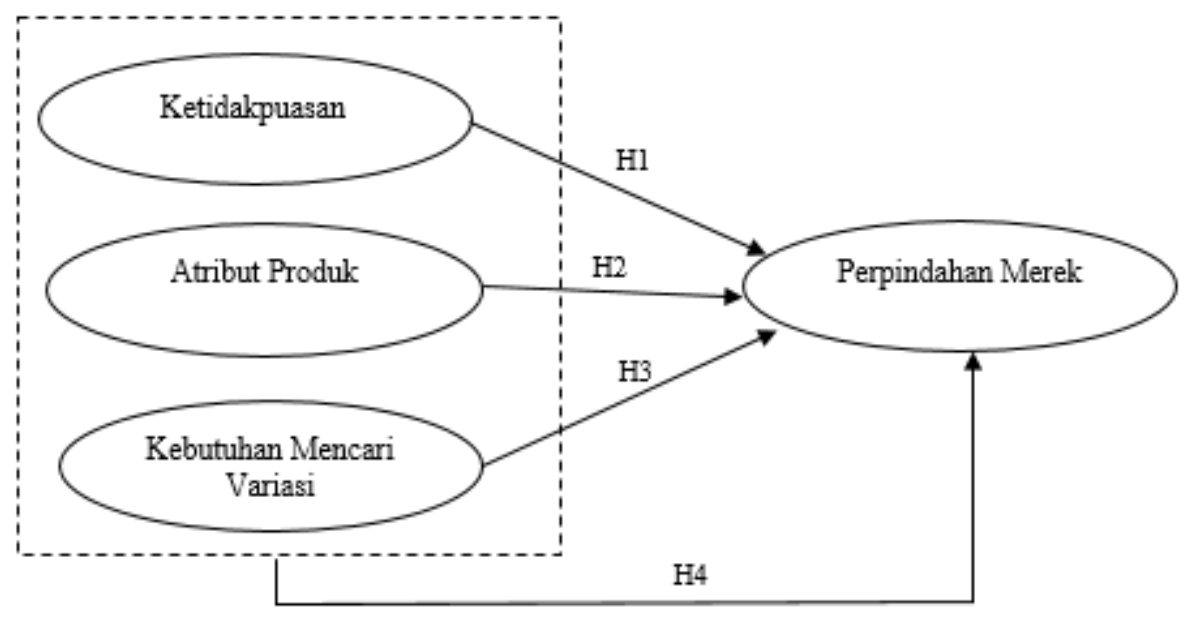

Gambar 1. Model Penelitian

\section{Rumusan Hipotesis Penelitian}

H1 : Diduga ketidakpuasan berpengaruh secara positif terhadap perpindahan merek.

H2 : Diduga atribut produk berpengaruh secara positif terhadap perpindahan merek.

H3 : Diduga kebutuhan mencari variasi berpengaruh secara positif terhadap perpindahan merek

H4 : diduga ketidakpuasan, atribut produk dan kebutuhan mencari variasi berpengaruh secara bersama-sama terhadap perpindahan merek. 


\section{Hasil Penelitian Dan Pembahasan}

\subsection{Data Responden}

Dalam penelitian ini responden dibagi dalam kelompok usia dan jenis kelamin, dengan penjelasan seperti dalam tabel berikut ini :

Tabel 2. Responden berdasar kelompok usia

\begin{tabular}{|c|c|c|}
\hline Usia & Jumlah responden (orang) & Persentase (\%) \\
\hline$\leq 20$ tahun & 21 & 21,8 \\
\hline $21-22$ tahun & 20 & 20,8 \\
\hline $23-24$ tahun & 26 & 27,0 \\
\hline $25-26$ tahun & 10 & 10,4 \\
\hline $27-28$ tahun & 10 & 10,4 \\
\hline $29-30$ tahun & 5 & 5,2 \\
\hline $31-32$ tahun & 3 & 3,1 \\
\hline $33-34$ tahun & 1 & 3,1 \\
\hline Jumlah & 96 & 100 \\
\hline
\end{tabular}

Sumber: Data primer yang diolah, 2021

Tabel 3. Responden berdasar kelompok jenis kelamin

\begin{tabular}{|c|c|c|}
\hline Jenis Kelamin & Jumlah responden (orang) & Persentase (\%) \\
\hline Laki-laki & 33 & 34,4 \\
\hline Perempuan & 63 & 65,6 \\
\hline Jumlah & 96 & 100 \\
\hline
\end{tabular}

Sumber: Data primer yang diolah, 2021

Tabel 4. Tanggapan Responden Terhadap Variabel Ketidakpuasan

\begin{tabular}{|c|c|c|c|c|c|c|c|c|c|c|c|c|}
\hline \multirow[b]{2}{*}{ Indikator } & \multicolumn{2}{|c|}{ STS } & \multicolumn{2}{|c|}{ TS } & \multicolumn{2}{|c|}{$\mathrm{N}$} & \multicolumn{2}{|c|}{$\mathrm{S}$} & \multicolumn{2}{|c|}{ SS } & \multirow{2}{*}{$\begin{array}{l}\text { Total } \\
\text { FxS }\end{array}$} & \multirow[b]{2}{*}{ Skor } \\
\hline & $F$ & $\mathrm{FxS}$ & $\mathrm{F}$ & $\mathrm{FxS}$ & $\mathrm{F}$ & FxS & $\mathrm{F}$ & FxS & $\mathrm{F}$ & FxS & & \\
\hline $\mathrm{X} 1.1$ & 0 & 0 & 10 & 20 & 27 & 81 & 38 & 152 & 21 & 105 & 358 & 71,6 \\
\hline $\mathrm{X} 1.2$ & 0 & 0 & 8 & 16 & 33 & 102 & 32 & 128 & 23 & 115 & 357 & 71,4 \\
\hline $\mathrm{X} 1.3$ & 0 & 0 & 9 & 18 & 32 & 96 & 29 & 119 & 26 & 130 & 363 & 72,6 \\
\hline & & & & & Rate & & & & & & & 71,8 \\
\hline
\end{tabular}

Sumber: Data primer yang diolah, 2021

Tabel 5. Tanggapan Responden Terhadap Variabel Atribut Produk

\begin{tabular}{|c|c|c|c|c|c|c|c|c|c|c|c|c|}
\hline \multirow[b]{2}{*}{ Indikator } & \multicolumn{2}{|c|}{ STS } & \multicolumn{2}{|c|}{ TS } & \multicolumn{2}{|c|}{$\mathrm{N}$} & \multicolumn{2}{|c|}{$\mathrm{S}$} & \multicolumn{2}{|c|}{ SS } & \multirow{2}{*}{$\begin{array}{l}\text { Total } \\
\text { FxS }\end{array}$} & \multirow[b]{2}{*}{ Skor } \\
\hline & $\mathrm{F}$ & FxS & F & $\mathrm{FxS}$ & F & FxS & F & FxS & $\mathrm{F}$ & FxS & & \\
\hline $\mathrm{X} 2.1$ & 0 & 0 & 8 & 16 & 34 & 102 & 32 & 128 & 22 & 110 & 356 & 71,2 \\
\hline $\mathrm{X} 2.2$ & 0 & 0 & 6 & 12 & 33 & 99 & 35 & 140 & 22 & 110 & 361 & 72,2 \\
\hline $\mathrm{X} 2.3$ & 0 & 0 & $\begin{array}{l}1 \\
0\end{array}$ & 20 & 33 & 99 & 31 & 124 & 22 & 110 & 353 & 70,6 \\
\hline & & & & & & & & & & & & 71,3 \\
\hline
\end{tabular}

Sumber: Data primer yang diolah, 2021

JURNAL ILMIAH KOMPUTERISASI AKUNTANSI Vol. 14, No. 2, Desember 2021 : $339-349$ 
Tabel 6. Tanggapan Responden Terhadap Variabel Kebutuhan

Mencari Variasi

\begin{tabular}{|c|c|c|c|c|c|c|c|c|c|c|c|c|}
\hline \multirow{2}{*}{ Indikator } & \multicolumn{2}{|c|}{ STS } & \multicolumn{2}{|c|}{ TS } & \multicolumn{2}{|c|}{$\mathrm{N}$} & \multicolumn{2}{|c|}{$\mathrm{S}$} & \multicolumn{2}{|c|}{ SS } & \multirow{2}{*}{$\begin{array}{l}\text { Total } \\
\text { FxS }\end{array}$} & \multirow[b]{2}{*}{ Skor } \\
\hline & F & FxS & $\mathrm{F}$ & FxS & $\mathrm{F}$ & FxS & $\mathrm{F}$ & FxS & $\mathrm{F}$ & FxS & & \\
\hline $\mathrm{X} 3.1$ & 0 & 0 & 8 & 16 & 35 & 105 & 31 & 124 & 22 & 110 & 355 & 71 \\
\hline $\mathrm{X} 3,2$ & 0 & 0 & 10 & 20 & 29 & 87 & 32 & 128 & 25 & 125 & 360 & 72 \\
\hline $\mathrm{X} 3,3$ & 0 & 0 & 8 & 16 & 32 & 96 & 33 & 132 & 23 & 115 & 358 & 71,6 \\
\hline \multicolumn{12}{|c|}{ Rata-rata } & 71,5 \\
\hline
\end{tabular}

Sumber: Data primer yang diolah, 2021

Tabel 7. Tanggapan Responden Terhadap Variabel Perpindahan Merek

\begin{tabular}{|c|c|c|c|c|c|c|c|c|c|c|c|c|}
\hline \multirow[b]{2}{*}{ Indikator } & \multicolumn{2}{|c|}{ STS } & \multicolumn{2}{|c|}{ TS } & \multicolumn{2}{|c|}{$\mathrm{N}$} & \multicolumn{2}{|c|}{$\mathrm{S}$} & \multicolumn{2}{|c|}{ SS } & \multirow{2}{*}{$\begin{array}{l}\text { Total } \\
\text { FxS }\end{array}$} & \multirow[b]{2}{*}{ Skor } \\
\hline & $\mathrm{F}$ & FxS & $\mathrm{F}$ & FxS & F & $\mathrm{FxS}$ & $\mathrm{F}$ & FxS & $\mathrm{F}$ & $\mathrm{FxS}$ & & \\
\hline Y.1 & 0 & 0 & 9 & 18 & 29 & 87 & 36 & 144 & 22 & 110 & 359 & 71,8 \\
\hline Y.2 & 0 & 0 & 10 & 20 & 32 & 96 & 33 & 132 & 21 & 105 & 353 & 70,6 \\
\hline Y.3 & 0 & 0 & 15 & 30 & 29 & 87 & 24 & 96 & 28 & 140 & 353 & 70,6 \\
\hline \multicolumn{12}{|c|}{ Rata-rata } & 71 \\
\hline
\end{tabular}

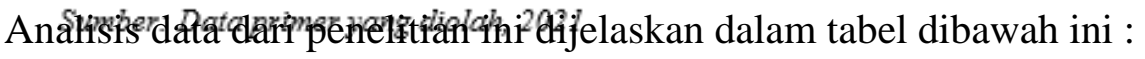

Tabel 8. Hasil Uji Validitas

\begin{tabular}{|c|c|c|c|c|}
\hline Variabel & Indikator & r.tabel & r.hitung & Ket \\
\hline \multirow{4}{*}{$\begin{array}{c}\text { Ketidakpuasan } \\
\text { (X1) }\end{array}$} & $\mathrm{X} 1.1$ & 0,2006 & 0,830 & valid \\
\cline { 2 - 5 } & $\mathrm{X} 1.2$ & 0,2006 & 0,746 & valid \\
\cline { 2 - 5 } & $\mathrm{X} 1.3$ & 0,2006 & 0,858 & valid \\
\hline \multirow{4}{*}{$\begin{array}{c}\text { Atribut Produk } \\
\text { (X2) }\end{array}$} & $\mathrm{X} 2.1$ & 0,2006 & 0,748 & valid \\
\cline { 2 - 5 } & $\mathrm{X} 2.2$ & 0,2006 & 0,818 & valid \\
\cline { 2 - 5 } & $\mathrm{X} 2.3$ & 0,2006 & 0,837 & valid \\
\hline \multirow{2}{*}{$\begin{array}{c}\text { Kebutuhan } \\
\text { Mencari Variasi } \\
(\mathrm{X} 3)\end{array}$} & $\mathrm{X} 3.1$ & 0,2006 & 0,840 & valid \\
\cline { 2 - 5 } & $\mathrm{X} 3.3$ & 0,2006 & 0,854 & valid \\
\hline \multirow{2}{*}{$\begin{array}{c}\text { Perpindahan } \\
\text { Merek } \\
(Y)\end{array}$} & $\mathrm{Y} .1$ & 0,2006 & 0,849 & valid \\
\cline { 2 - 5 } & $\mathrm{Y} .1$ & 0,2006 & 0,842 & valid \\
\cline { 2 - 5 } & $\mathrm{Y} .1$ & 0,2006 & 0,810 & valid \\
\hline
\end{tabular}

Sumber: Data primer yang diolah, 2021 
Tabel 9. Hasil Uji Reliabilitas

\begin{tabular}{|c|c|c|c|}
\hline Variabel & Indikator & $\begin{array}{c}\text { Cronbach's } \\
\text { Alpha }\end{array}$ & Keterangan \\
\hline \multirow{4}{*}{$\begin{array}{c}\text { Ketidakpuasan } \\
\text { (X1) }\end{array}$} & $\mathrm{X} 1.1$ & 0,776 & reliabel \\
\cline { 2 - 4 } & $\mathrm{X} 1.2$ & 0,817 & reliabel \\
\cline { 2 - 4 } & $\mathrm{X} 1.3$ & 0,780 & reliabel \\
\hline \multirow{3}{*}{$\begin{array}{c}\text { Atribut Produk } \\
(\mathrm{X} 2)\end{array}$} & $\mathrm{X} 2.1$ & 0,811 & reliabel \\
\cline { 2 - 4 } & $\mathrm{X} 2.2$ & 0,786 & reliabel \\
\hline \multirow{2}{*}{$\begin{array}{c}\text { Kebutuhan } \\
\text { Mencari Variasi } \\
(\mathrm{X} 3)\end{array}$} & $\mathrm{X} 2.3$ & 0,766 & reliabel \\
\cline { 2 - 4 } & $\mathrm{X} 3.2$ & 0,809 & reliabel \\
\hline \multirow{2}{*}{$\begin{array}{c}\text { Perpindahan } \\
\text { Merek } \\
(Y)\end{array}$} & $\mathrm{X} 3.3$ & 0,802 & reliabel \\
\cline { 2 - 4 } & $\mathrm{Y} .2$ & 0,791 & reliabel \\
\cline { 2 - 4 } & $\mathrm{Y} .3$ & 0,797 & reliabel \\
\hline
\end{tabular}

Sumber: Data primer yang diolah, 2021

Tabel 10. Hasil Uji Normalitas

\begin{tabular}{|llr|}
\hline \multicolumn{2}{|c|}{ One-Sample Kolmogorov-Smimov Test } \\
\hline N & \multicolumn{1}{c|}{$\begin{array}{c}\text { Unstandardized } \\
\text { Residual }\end{array}$} \\
\hline Normal Parameters & & 96 \\
& Mean & .0000000 \\
& Std. Deviation & 1.08934579 \\
Most Extreme Differences & Absolute & .042 \\
& Positive & .042 \\
Kolmogorov-Smimov Z & Negative & -.037 \\
Asymp. Sig. (2-tailed) & & .411 \\
a. Test distribution is Normal. & & .996 \\
b. Calculated from data. & \\
\hline
\end{tabular}

Sumber: Data primer yang diolah, 2021

Tabel 11. Hasil Uji Heteroskedastisitas Coefficients $^{2}$

\begin{tabular}{|c|c|c|c|c|c|c|}
\hline \multirow{2}{*}{\multicolumn{2}{|c|}{ Model }} & \multicolumn{2}{|c|}{$\begin{array}{l}\text { Unstandardized } \\
\text { Coefficients }\end{array}$} & \multirow{2}{*}{$\begin{array}{c}\begin{array}{c}\text { Standardized } \\
\text { Coefficients }\end{array} \\
\text { Beta }\end{array}$} & \multirow[t]{2}{*}{$\mathrm{t}$} & \multirow[t]{2}{*}{ Sig. } \\
\hline & & B & $\begin{array}{l}\text { Std. } \\
\text { Error }\end{array}$ & & & \\
\hline \multirow{4}{*}{1} & (Constant) & .351 & .377 & & .930 & .355 \\
\hline & Ketidakpuasan & .056 & .048 & .201 & 1.177 & .242 \\
\hline & Atribut Produk & .005 & .050 & .014 & .090 & .929 \\
\hline & Kebutuhan Mencari Variasi & .014 & .045 & .049 & .301 & .764 \\
\hline
\end{tabular}

a. Dependent Variable: RES2 
Tabel 12. Hasil Uji Multikolinearitas

\begin{tabular}{|c|c|c|c|}
\hline \multirow{2}{*}{ No } & \multirow{2}{*}{ Variabel Penelitian } & \multicolumn{2}{|c|}{$\begin{array}{c}\text { Collinearity } \\
\text { Statistic }\end{array}$} \\
\cline { 3 - 4 } & & Tolerance & VIF \\
\hline 1 & Ketidakpuasan & 0,407 & 2,456 \\
\hline 2 & Atribut Produk & 0,360 & 2,775 \\
\hline 3 & $\begin{array}{c}\text { Kebutuhan Mencari } \\
\text { Variasi }\end{array}$ & 0,388 & 2.575 \\
\hline \multicolumn{3}{|c|}{ Sumber: Data primer yang diolah, 2021 }
\end{tabular}

\subsection{Persamaan Regresi}

Tabel 13. Persamaan Regresi Linier

\section{Coefficients $^{2}$}

\begin{tabular}{|c|c|c|c|c|c|}
\hline \multirow[t]{2}{*}{ Model } & \multicolumn{2}{|c|}{ Unstandardized Coefficients } & $\begin{array}{l}\text { Standardized } \\
\text { Coefficients }\end{array}$ & \multirow[t]{2}{*}{$\mathrm{t}$} & \multirow[t]{2}{*}{ Sig. } \\
\hline & B & Std. Error & Beta & & \\
\hline (Constant) & .064 & .644 & & .100 & .921 \\
\hline Ketidakpuasan & .290 & .081 & .288 & 3.575 & .001 \\
\hline$\underset{\text { Atribut Produk }}{\text { ersamaan regresi linier dal }}$ & am penelitif & in ini adala & .179 & 2.362 & .020 \\
\hline $\mathrm{Y}=\mathrm{a}+\mathrm{b} 1 \mathrm{X} 1+\mathrm{b} 2 \mathrm{X} 2$ & $+\mathrm{b} 3 \mathrm{X} 3+$ & & .502 & 6.472 & .000 \\
\hline
\end{tabular}

Sumber: Data primer yang diolah, 2021

Dari persamaan tersebut diatas, dapat dijelaskan sebagi berikut :

Hasil persamaan regresi tersebut di atas dapat diartikan sebagai berikut:

1. Variabel atribut produk berpengaruh positif dan signifikan. Memberikan pengertian bahwa semakin menarik atribut produk pada produk pesaing, maka akan semakin tinggi pula keinginan konsumen untuk melakukan perpindahan merek.

2. Variabel ketidakpuasan berpengaruh positif dan signifikan. Memberikan pengertian bahwa semakin tinggi ketidakpuasan yang dirasakan oleh konsumen maka keputusan konsumen untuk berpindah merek juga semakin tinggi.

3. Variabel kebutuhan mencari variasi berpengaruh positif dan signifikan. Memberikan pengertian bahwa semakin tinggi kebutuhan mencari variasi, maka akan semakin tinggi pula keinginan konsumen untuk melakukan perpindahan merek.

Berdasarkan hasil analisis regresi linier berganda menunjukkan bahwa variabel citra merek memberikan pengaruh yang paling besar terhadap perpindahan merek. 


\section{Tabel 14. Uji Hipotesis}

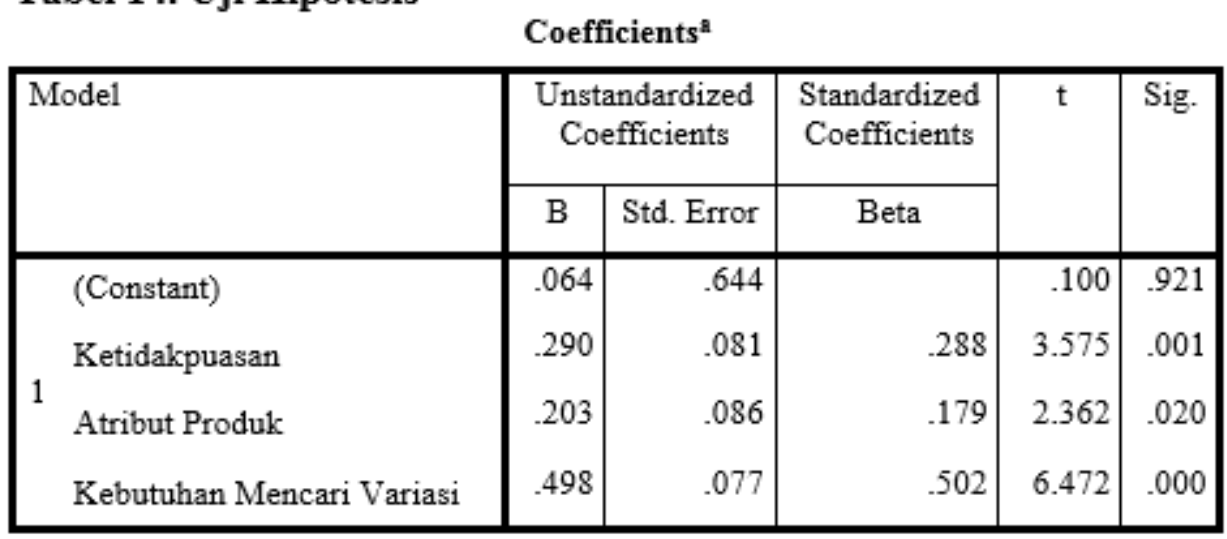

a. Dependent Variable: Perpindahan Merek

Sumber: Data primer yang diolah, 2021

Dari tabel 14 dapat dijelaskan bahwa nilai probabilitas masing-masing variabel adalah sebagai berikut :

Variabel Ketidakpuasan $\left(\mathrm{X}_{1}\right)$

Hasil pengujian diperoleh nilai thitung dari ketidakpuasan sebesar 3,575 dengan probabilitas signifikansi sebesar 0,001 . Yang berarti dapat dikatakan bahwa secara parsial ketidakpuasan berpengaruh positif dan signifikan terhadap perpindahan merek.

Variabel Atribut Produk $\left(\mathrm{X}_{2}\right)$

Hasil pengujian diperoleh nilai $t_{\text {hitung }}$ dari atribut produk sebesar 2,362 dengan probabilitas signifikansi sebesar 0,020. Yang berarti dapat dikatakan bahwa secara parsial atribut produk berpengaruh positif dan signifikan terhadap perpindahan merek.

Variabel Kebutuhan Mencari Variasi $\left(\mathrm{X}_{3}\right)$

Hasil pengujian diperoleh nilai thitung dari kebutuhan mencari variasi sebesar 6,472 dengan probabilitas signifikansi sebesar 0,000. Yang berarti dapat dikatakan bahwa secara parsial kebutuhan mencari variasi berpengaruh positif dan signifikan terhadap perpindahan merek.

\section{Tabel 15. Uji F (Simultan)}

\begin{tabular}{|l|r|r|r|r|r|}
\hline Model & $\begin{array}{c}\text { Sum of } \\
\text { Squares }\end{array}$ & df & $\begin{array}{c}\text { Mean } \\
\text { Square }\end{array}$ & F & Sig. \\
\hline . Regression & 411.422 & 3 & 137.141 & 111.918 & $.000^{\mathrm{b}}$ \\
1 Residual & 112.734 & 92 & 1.225 & & \\
$\quad$ Total & 524.156 & 95 & & & \\
\hline
\end{tabular}

a. Dependent Variable: Perpindahan Merek

b. Predictors: (Constant), Kebutuhan Mencari Variasi, Atribut Produk, Ketidakpuasan

Sumber: Data primer yang diolah, 2021

JURNAL ILMIAH KOMPUTERISASI AKUNTANSI Vol. 14, No. 2, Desember $2021: 339-349$ 
Berdasarkan hasil uji F pada tabel di atas, menunjukkan nilai $F_{h i t u n g}$ sebesar 111,918 dengan probabilitas signifikansi sebesar 0,000 . Yang berarti dapat dikatakan bahwa ketidakpuasan, atribut produk, dan kebutuhan mencari variasi berpengaruh secara simultan terhadap perpindahan merek.

\section{Tabel 16 Koefisien Determinasi $\left(R^{2}\right)$}

Model Summary b

\begin{tabular}{|l|r|r|r|r|}
\hline Model & R & R Square & $\begin{array}{c}\text { Adjusted R } \\
\text { Square }\end{array}$ & $\begin{array}{c}\text { Std. Error of the } \\
\text { Estimate }\end{array}$ \\
\hline 1 & $.886^{2}$ & .785 & .778 & 1.107 \\
\hline
\end{tabular}

a. Predictors: (Constant), Kebutuhan Mencari Variasi, Atribut Produk,

Ketidakpuasan

b. Dependent Variable: Perpindahan Merek

Sumber: Data primer yang diolah, 2021

Berdasarkan hasil perhitungan pada tabel di atas, menunjukkan bahwa nilai Adjusted RSquere yang diperoleh sebesar 0,778 . Dalam hal ini berarti $77,8 \%$ variasi variabel perpindahan merek dijelaskan oleh variabel ketidakpuasan, atribut produk, dan kebutuhan mencari variasi Sedangkan sisanya 22,2\% dijelaskan oleh variabel lain di luar model.

\section{Kesimpulan Dan Saran}

\subsection{Keseimpulan}

Dari pembahasan maka dapat ditarik kesimpulan sebagai berikut:

1. Variabel ketidakpuasan berpengaruh positif dan signifikan terhadap perpindahan merek, artinya bahwa semakin tinggi ketidakpuasan yang dirasakan oleh konsumen maka keputusan konsumen untuk berpindah merek juga semakin tinggi.

2. Variabel Atribut produk berpengaruh positif dan signifikan terhadap perpindahan merek, artinya bahwa bahwa semakin menarik atribut produk pada produk pesaing, maka akan semakin tinggi pula keinginan konsumen untuk melakukan perpindahan merek

3. Variabel Kebutuhan mencari variasi berpengaruh positif dan signifikan terhadap perpindahan merek, artinya bahwa semakin tinggi kebutuhan konsumen untuk mencari varasi produk, maka akan semakin tinggi pula keinginan konsumen untuk melakukan perpindahan merek.

\subsection{Saran}

Dari uraian diatas, ada beberapa saran untuk vendor smartphone Asus jika tidak ingin semakin ditinggal oleh penggemar setianya. Beberapa catatan itu antara lain sebagai berikut:

1. Perusahaan harus mengerti selera konsumen dalam memilih smartphone, misalnya dengan menciptakan Asus dengan tampilan yang simpel dan mudah digunakan dan desain selalu mengikuti perkembangan jaman up to date, sehingga dapat mencegah konsumen beralih ke smartphone lain, semakin tinggi ketidakpuasan yang dirasakan oleh konsumen maka keputusan konsumen untuk berpindah merek juga semakin tinggi. 
2. Perusahaan harus lebih untuk meningkatkan unsur-unsur produk yang dipandang penting oleh konsumen dan dijadikan dasar pengambilan keputusan pembelian. Dalam pengukuran kepuasan konsumen, atribut atau fitur produk berperan penting karena itu terdapat beberapa cara yang dapat digunakan oleh peneliti untuk menentukan atribut produk, salah satunya adalah dengan menanyakan kepada konsumen atribut atau fitur apa saja yang dianggap penting

3. Pada variabel kebutuhan mencari variasi, Perlunya meningkatkan kualitas dan melakukan inovasi-inovasi, misalnya dengan menciptakan produk Asus dengan baterai yang lebih tahan lama dibanding pesaing, menciptakan produk dengan tampilan yang simple mudah dijalankan seperti halnya produk dari android. Hal tersebut bertujuan untuk menarik minat masyarakat atau mempertahankan merek smartphone Asus, maka dengan demikian semakin tinggi kebutuhan konsumen untuk mencari varasi produk, maka akan semakin tinggi pula keinginan konsumen untuk melakukan perpindahan merek.

\section{DAFTAR PUSTAKA}

\section{Referensi Cetak :}

Buku

[1].Durianto, Darmadi, dkk. 2014. Strategi Menaklukkan Pasar. Jakarta: PT. Gramedia Pustaka Utama.

[2].Ghozali, Imam. 2012. Aplikasi Analisis Multivariate Dengan Program SPSS 20. Semarang: Universitas Diponegoro

[3].Jefkins, Frank. 1996. Periklanan. Edisi 3. Jakarta: Erlangga

[4].John C. Mowen, Michael Minor, 2012, Perilaku Konsumen, Jakarta: Erlangga

[5].Kotler, Philip dan Kevin Lane Keller. 2014. Manajemen Pemasaran. Edisi 13. Jakarta: Erlangga.

[6].Kotler, Philip. 2015. Manajamen Pemasaran, Jilid 1. Jakarta: PT. Indeks Kelompok Gramedia.

[7].Peter, Paul J dan Olson Jerry C. 2002. Perilaku Konsumen dan Strategi Pemasaran. Edisi ke Empat. Jakarta: Erlangga

[8].Setiadi, Nugroho J. 2013. Konsep dan Implikasi Untuk Strategi dan Penelitian Pemasaran. Jakarta: Prenada Media

[9]Shimp, Terrence A. 2013. Periklanan Promosi. Edisi Kelima. Jakarta: Erlangga.

[10]. Sugiyono. 2014. Statistika Untuk Penelitian. Bandung: CV. Alfabeta.

[11].Tjiptono, Fandy. 2014. Manajemen Jasa. Edisi Kedua. Yogyakarta: Andi Offset.

[12].Tjiptono, Fandy. 2016. Strategi Pemasaran. Yogyakarta: Andi.

Jurnal

[1]. Arianto, Anandhitya Bagus. 2016. Pengaruh Atribut Produk, Harga, Kebutuhan Mencari Variasi dan Ketidakpuasan Konsumen terhadap Keputusan Perpindahan Merek dari Samsung Galaxy Series di Kota Malang. Jurnal Aplikasi Manajemen. Vol. 11, No. 2.

[2].Dewi, Pramesti Kharisma. 2014. Analisis Pengaruh Atribut Produk, Perilaku Mencari Variasi, dan Promosi terhadap Perilaku Perpindahan Merek (Studi Kasus pada Ex Pengguna Smartphone Merek BlackBerry di Semarang). Skripsi, tidak diterbitkan. Universitas Diponegoro Semarang

JURNAL ILMIAH KOMPUTERISASI AKUNTANSI Vol. 14, No. 2, Desember 2021 : $339-349$ 
[3].Eka, Rita dan AR Saliman. 2015. Periklanan Yang Efektif. Jurnal Ekonomi Perusahaan. Vol.8, No.2

[4].Irawan, Andry, dkk. 2015. "Pengaruh Kualitas Fitur, Desain, Iklan, Kepuasan Konsumen dan Kebutuhan Mencari Variasi terhadap Keinginan Berpindah Merek Handpone (Survai Pada Pengguna Handphone Di Kota Purwokerto)", PERFORMANCE: Vol. 11 No.1 Maret 2010 (p.83-106)

[5].Khasanah, Aulia Uswatun. 2014. Analisis Faktor-Faktor Yang Mempengaruhi Perpindahan Merek Pada Produk Smartphone (Studi Kasus pada Mahasiswa Universitas Muhammadiyah Surakarta yang Melakukan Perpindahan Merek dari Blackberry ke non Blackberry). ISBN: 978-602-70429-1-9.

[6].Kosidah, Sri. 2014. Analisis Faktor-Faktor yang Mempengaruhi Perilaku Brand Switching pada Kartu Prabayar XL (Studi pada konsumen Pandumedia Reload Service Singosari-Malang). Jurnal Sketsa Bisnis. Vol. 1, No. 1.

[7].Lestari, Diana Vita. 2015. “Analisis Pengaruh Ketidakpuasan Konsumen, Kebutuhan Mencari Variasi, Keterlibatan Konsumen, Harga dan Daya Tarik Pesaing Terhadap Perilaku Brand Switching (Studi Kasus pada Pengguna Telepon Seluler Sony Ericsson di Kota Semarang)". Skripsi. Semarang: Universitas Diponegoro

[8].Masitha, Merry Agil. 2014. Pengaruh Harga, Variasi Produk, Ketidakpuasan Konsumen Dan Iklan Pesaing Terhadap Perpindahan Merek. Jurnal Ilmu dan Riset Manajemen. Vol. 3, No. 1. 